\title{
Meal pattern among Norwegian primary-school children and longitudinal associations between meal skipping and weight status
}

\author{
Tonje H Stea ${ }^{1, *}$, Frøydis N Vik ${ }^{1}$, Elling Bere ${ }^{1}$, Martin V Svendsen ${ }^{2}$ and \\ Inger $M$ Oellingrath ${ }^{3}$ \\ 'Department of Public Health, Sport and Nutrition, University of Agder, Postboks 422, N-4604 Kristiansand, \\ Norway: ${ }^{2}$ Department of Occupational Medicine, Telemark Hospital, Skien, Norway: ${ }^{3}$ Department of Health \\ Studies, Telemark University College, Porsgrunn, Norway
}

Submitted 4 February 2013: Final revision received 9 September 2013: Accepted 10 January 2014: First published online 13 February 2014

\begin{abstract}
Objective: To investigate meal pattern longitudinally and explore whether meal skipping was associated with overweight among Norwegian children and adolescents.

Design: Longitudinal study. Children's meal frequencies were reported by their parents using a retrospective FFQ. Weight and height were measured by public health nurses. Descriptive data comparing 4th and 7th grade were analysed by paired-sample $t$ tests for continuous variables and $\chi^{2}$ tests for categorical variables. Odds ratio estimates, including confidence intervals, with BMI category (normal/overweight) as the dependent variable, were determined through logistic regression analyses.

Setting: Primary schools, Telemark County, Norway.

Subjects: A cohort of 428 Norwegian boys and girls; 4th graders in 2007, 7 th graders in 2010 .

Results: The number of children eating four main meals per day (regular meal frequency) decreased from 4 th grade $(47 \%)$ to 7 th grade $(38 \% ; P=0 \cdot 001)$. Those who ate regular meals in 4 th grade but not in 7 th grade had higher odds $(\mathrm{OR}=3 \cdot 1 ; 95 \% \mathrm{CI} 1 \cdot 1,9 \cdot 0)$ of being overweight in 7 th grade after adjusting for gender, maternal education and physical activity, but the odds ratio was not statistically significant after adjusting for overweight in 4 th grade $(\mathrm{OR}=2 \cdot 8 ; 95 \%$ CI $0 \cdot 7,11 \cdot 6$ ).

Conclusions: The present study showed significant increases in overall meal skipping among children between 4th and 7 th grade. The results indicate an association between overweight and meal skipping, but additional prospective and longitudinal analyses and intervention trials are warranted to confirm this relationship.
\end{abstract}

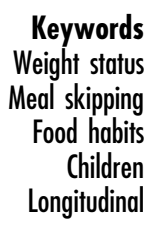

Eating regular meals is one of the potential energy balance-related behaviours ${ }^{(1)}$. Meals are often defined as eating breakfast, lunch, dinner and small snacks such as mid-morning, mid-afternoon and evening ${ }^{(2)}$. Main meals are in many countries breakfast, lunch and dinner, but can differ; e.g. in Norway there is usually a fourth main meal: evening meal (served in the evening due to an earlier dinner compared with most countries). Children's meal pattern in the USA have changed over a two-decade period, making skipping of meals more prevalent ${ }^{(3)}$. Unhealthy dietary habits, including irregular breakfast eating, have also been reported among Norwegian adolescents $^{(4,5)}$. Worldwide, the prevalence of obesity increased dramatically during the last decades ${ }^{(6-9)}$, although new findings support a levelling off in children and adolescents from Australia, Europe, Japan and the $\mathrm{USA}^{(10)}$. In Norway, increasing prevalence of overweight has been observed in children and adolescents over the last decades ${ }^{(11)}$. Still, there is overwhelming agreement that the levels of overweight and obesity among children are too high.

High meal frequency ( 4 or $5 v$. $\leq 3$ meals/d) has been observed to be inversely associated with childhood obesity in cross-sectional studies ${ }^{(2,12-14)}$. Longitudinal associations between a regular meal pattern/high meal frequency and obesity are scarce in this field, but a 10-year observational study among American adolescent girls revealed that a frequency of $3+$ meals/d was positively related to a lower 
BMI-for-age $Z$-score ${ }^{(15)}$. The study also revealed that the percentage of girls skipping meals increased from the age of 9 to 19 years $^{(15)}$.

Food habits and meal patterns, which are learned and acquired in childhood, tend to persist into later ages. Evidence also shows that childhood overweight tracks into adulthood ${ }^{(16)}$. Therefore, a focus on eating regular meals could be a possible target for early prevention of overweight and obesity in children and possible longitudinal associations are of particular interest to investigate causality.

The aims of the present study were to: (i) assess the meal pattern of Norwegian schoolchildren in 4th and 7 th grade and describe longitudinal changes; and (ii) assess the association between meal skipping and overweight.

\section{Methods}

\section{Participants and study design}

The present data were obtained from a study of primaryschool pupils in Telemark County, Norway. Data collection took place in the spring of 2007 and spring of 2010, when the children were in primary school grades 4 (9-10 years old) and 7 (12-13 years old), respectively. The detailed methods for the 4th grade data collection have been described previously ${ }^{(17)}$. An identical procedure was used for data collection in the 7 th grade ${ }^{(18)}$.

In brief, all primary schools in Telemark County were invited to participate in the study at both time points. In 2007 (4th grade), 110 schools were invited and seventy agreed to participate. Due to merging of some schools in the period between the two data collection points, 104 schools were invited in 2010 and fifty-three agreed to participate. Of the fifty-three schools participating in 2010, forty-six also attended in 2007 and six schools were new participants.

In total, written parental consent to inclusion in the study was received for 1045 out of 1477 invited children in the 4th grade and 1095 out of 1503 invited children in the 7 th grade. This represented about half of the county's 4 th and 7 th grade pupils at the respective time points.

Weight and height measurements were obtained for 955 (4th grade) and 865 ( 7 th grade) children, while complete weight/height and meal frequency data were obtained for 924 and 690 pupils, respectively. In total, 428 children (207 boys and 221 girls) provided complete weight, height and meal frequency data at both time points.

The study was conducted according to the guidelines laid down in the Declaration of Helsinki and ethical approval and research clearance were obtained from the Norwegian Social Science Data Services. The parents and the children received separate information letters. The parents gave their written consent to participate including a confirmation that their child wanted to participate too.

\section{Dietary information}

The children's habitual daily consumption of main meals (breakfast, lunch, dinner and evening meal) during the last 6 months was reported by their parents using a retrospective FFQ that included information about meal frequencies. Meal frequencies were registered with eight response alternatives ranging from 'never/rarely' to 'daily'. The questionnaire was based on a short FFQ developed for use with children in grades 4 and 8 in Norway $^{(19)}$, but was modified to include more dietary questions. Before the study, the FFQ was tested on a sample of parents and followed up by qualitative interviews $^{(20)}$. Identical FFQ were used at both time points and the questionnaires were distributed at school and returned to school.

The numbers of days reported eating breakfast, lunch, dinner and evening meals were then collapsed into dichotomous variables. Children who ate these main meals fewer than $7 \mathrm{~d}$ /week were classified as breakfast, lunch, dinner and evening-meal skippers, respectively. Children who ate these main meals every day were classified as regular breakfast, lunch, dinner and eveningmeal consumers. These dichotomous variables were then combined to create a summary variable referred to as 'all regular meals', i.e. those eating all meals (1) $v$. those skipping meals (0) in respectively 4 th and 7 th grade. For the longitudinal analyses in the present study, the children were further categorized into a new variable to describe meal skipping longitudinally, giving a variable of four categories: (i) CONTINUED skippers (skipping meals at both time points); (ii) START all meals (meals skippers in 4th grade, eat all meals in 7th grade); (iii) STOP all meals (eat all meals in 4th grade, meal skippers in 7th grade); and (iv) ALL meals (eat all meals at both time points).

\section{Other variables}

To measure physical activity, the parents provided information about how many hours their children spent on sports or exercise that made them sweat or feel breathless outside school, with response alternatives ranging from 'none' to 'seven hours or more during a normal week'.

Maternal educational level was collected by asking for the highest completed education and divided into three categories: (i) 'primary and lower secondary education' (10 years or less); (ii) 'upper secondary education' (3 to 4 years of secondary education); and (iii) 'university or university college'.

\section{BMI categories}

The weight and height of all the participating children were measured by public health nurses at each school at both time points. The children were weighed wearing light clothing (i.e. trousers, T-shirt, socks), using identical calibrated, electronic scales measuring in $100 \mathrm{~g}$ increments. BMI $\left(\mathrm{kg} / \mathrm{m}^{2}\right)$ of each child was calculated on the basis of 
these measurements. Child BMI categories (underweight, normal weight, overweight, obese) were calculated using sex- and age-specific cut-off points of the International Obesity Task Force ${ }^{(21,22)}$. Due to small numbers, we included underweight children in the normal-weight group and obese children in the overweight group.

\section{Statistics}

Descriptive data comparing 4th and 7th graders in Norway were analysed by paired-sample $t$ tests for continuous variables and $\chi^{2}$ tests for categorical variables. Four separate groups were described (i.e. CONTINUED skippers, START all meals, STOP all meals and ALL meals). ALL meals, as the preferred meal pattern, was compared with the rest of the study sample. Odds ratio estimates, including confidence intervals, with weight status as the dependent variable, were determined through logistic regression analyses (Table 2). All of the following logistic regression models were adjusted for maternal education and gender. Furthermore, model 1 included meal pattern (CONTINUED skippers, START all meals, STOP all meals $v$. ALL meals as the reference; Table 2). Model 2 included meal pattern and physical activity and model 3 included meal pattern, physical activity and overweight status in 4th grade (Table 2). All statistical analyses were performed using the statistical software package IBM SPSS Statistics 19•0.

\section{Results}

The children with complete data in both 4th and 7th grade were generally from families with somewhat higher educational level than those without complete data $(56 \%$ $v$. $51 \%$ of the parents, respectively, had 'university or university college'; $P=0 \cdot 003$ ). No difference in participation with regard to gender was observed.

In 4th grade, a total of 203 (47\%) of the children were reported to eat all four meals every day whereas 146 (34\%), sixty-six (15\%), eleven (3\%) and two (1\%) children ate three, two, one or none of these main meals every day during a week, respectively. In 7 th grade, a total of 166 (38\%) of the children were reported to eat all four meals every day whereas 143 (33\%), ninety-one (21\%), twenty-two (5\%) and eight (2\%) children ate three, two, one or none of the main meals every day during a week, respectively.

In both 4th and 7th grade, approximately $90 \%$ of the children had regular breakfast habits and $85 \%$ consumed dinner regularly (Table 1 ). Further, the results showed a significant decrease in the proportion reporting to eat regular lunch meals, from $81 \%$ to $75 \%(P=0 \cdot 010)$, and regular evening meals, from $67 \%$ to $53 \%(P<0 \cdot 001)$, between 4 th and 7 th grade. Thus, the frequency of children who ate all four main meals regularly decreased significantly from 4 th grade $(47 \%)$ to 7 th grade $38 \%$; $P=0 \cdot 001)$. No gender differences in meal skipping were observed in 4 th grade or 7 th grade (data not shown). A significant increase in physical activity $(P<0 \cdot 001)$, but no change in the overweight prevalence among children was observed from 4 th to 7 th grade (Table 1 ). Tracking of 4th grade overweight/obese children ( $n$ 68) showed that forty-four (65\%) remained overweight/ obese in 7 th grade (Fig. 1). Among the 4th grade normalweight children ( $n$ 360), 339 (94\%) remained normal weight and twenty-one (6\%) became overweight/obese in 7 th grade (Fig. 1).

Among the total sample, $41 \%$ of the children skipped meals in both 4 th and 7 th grade (CONTINUED skippers) whereas $11 \%$ reported to eat all meals only in 7 th grade (START all meals) and $21 \%$ reported to eat all meals only in 4 th grade (STOP all meals; data not shown). A total of $27 \%$ of the children reported to eat all meals (ALL meals) at both time points (data not shown).

Those included in the category STOP all meals did have greater odds of being overweight in 7 th grade, adjusting for sex, maternal education and physical activity, than those who ate ALL meals (OR $=3 \cdot 1 ; 95 \%$ CI $1 \cdot 1,9 \cdot 0)$, but the odds ratio was not statistically significant after adjusting for overweight in 4 th grade (Table 2). The odds of being

Table 1 Descriptive data of the study sample of primary-school children (4th graders in 2007, 7th graders in 2010), Telemark County, Norway ( $n$ 428)

\begin{tabular}{|c|c|c|c|}
\hline & 4 th grade & 7 th grade & $P$ value* \\
\hline \multicolumn{4}{|l|}{ BMI category } \\
\hline Underweight (\%) & 3 & 1 & 0.655 \\
\hline Normal weight (\%) & 81 & 85 & \\
\hline Overweight (\%) & 14 & 12 & \\
\hline Obese (\%) & 2 & 3 & \\
\hline Physical activity outside school (h/week) & $3 \cdot 3$ & $4 \cdot 5$ & $<0.001$ \\
\hline $95 \% \mathrm{Cl}$ & $3 \cdot 3,3 \cdot 4$ & $4 \cdot 4,4 \cdot 7$ & \\
\hline \multicolumn{4}{|l|}{ Meal pattern } \\
\hline Regular breakfast (\%) & 91 & 90 & 0.263 \\
\hline Regular lunch (\%) & 81 & 75 & 0.010 \\
\hline Regular dinner (\%) & 85 & 84 & 0.569 \\
\hline Regular evening meal (\%) & 67 & 53 & $<0.001$ \\
\hline Regular all 4 meals (\%) & 47 & 38 & 0.001 \\
\hline
\end{tabular}

*Paired-sample $t$ test was used to analyse changes in physical activity and $\chi^{2}$ tests were used to analyse changes in all other variables. 
overweight in 7 th grade among those included in the categories START all meals and CONTINUED skippers was not significantly different from those who ate all meals.

\section{Discussion}

The present study showed an overall increase in meal skipping with increasing age. While the frequency of breakfast and dinner skippers remained relatively stable (approximately 10\% and 16\%, respectively), significant increases in skipping lunch (from 19\% to 25\%) and evening meals (from 33\% to $47 \%$ ) were reported between 4 th and 7 th grade. Few other studies have described longitudinal changes in meal pattern among children and adolescents.

In agreement with results from the present study, a crosssectional study among children of pre-school age in Canada reported that one-tenth of the children ate breakfast on fewer than $7 \mathrm{~d} /$ week $^{(23)}$. An American study showed

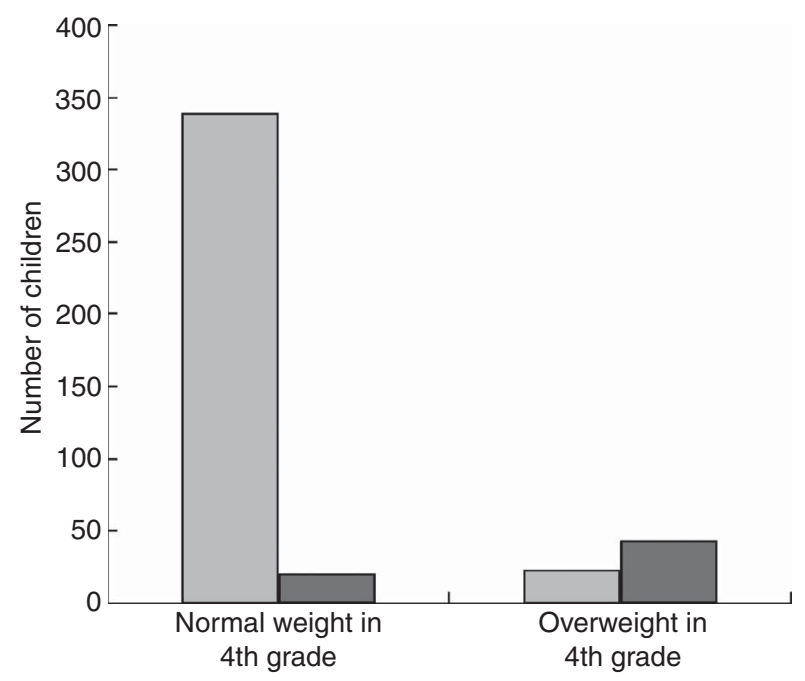

Fig. 1 Changes in BMI status between 4th and 7th grade among a sample of primary-school children (4th graders in 2007,7 th graders in 2010), Telemark County, Norway ( $n$ 428): $\square$, normal weight in 7 th grade; $\square$, overweight in 7 th grade that $20 \%$ of 4 th grade students were skipping breakfast and/or lunch at least three times per week ${ }^{(15)}$, whereas a Finnish study reported that practically all children between 10 and 11 years old (99\%) had breakfast, 94\% had lunch and $80 \%$ had dinner regularly ${ }^{(24)}$. Among Swedish adolescents in 9th grade, only $76 \%$ of girls and $88 \%$ of boys reported to eat breakfast regularly ${ }^{(25)}$. Unhealthy dietary habits, including irregular breakfast eating, have also been reported among Norwegian adolescents ${ }^{(4,5)}$.

In addition to age- and regional-related trends, studies from the 1970s to today have reported a tendency towards a decrease in meal frequency and going from regular meals to skipping main meals among children and adolescents $^{(3,26)}$.

The relationship between meal pattern and overweight has been widely debated; several cross-sectional studies have observed a positive association between meal skipping and the prevalence of overweight ${ }^{(2,25,27-30)}$, while others have not supported these associations ${ }^{(3)}$. However, few longitudinal studies have been published. We have previously shown that children adhering to a 'varied Norwegian' eating pattern, which included regular breakfast and eating lunch, were less likely to remain overweight ${ }^{(18)}$. The present study showed that those who stopped eating regular meals after 4th grade were three times more likely to be overweight in 7 th grade compared with those who ate regular meals in both 4th and 7th grade after adjusting for physical activity. However, this relationship did not remain significant after adjusting for overweight in 4th grade, but remained of comparable amplitude. Not surprisingly, overweight in 4th grade appeared to be the most important predictor of overweight in 7 th grade. We have previously reported a high degree of BMI tracking from 4th to 7 th grade in the same cohort $^{(18)}$. However, adjusting for physical activity had a larger impact than overweight at 4th grade on the estimated odds ratios for meal skipping. This indicates an important association between physical activity, regular meal pattern and overweight.

Other longitudinal studies have reported an inverse relationship between meal frequency and $\mathrm{BMI}^{(10,19,31-33)}$,

Table 2 Logistic regression models describing odds of being overweight in 7th grade, adjusted for physical activity and overweight in 4th grade, among a sample of primary-school children (4th graders in 2007, 7th graders in 2010), Telemark County, Norway ( $n$ 428)

\begin{tabular}{|c|c|c|c|c|c|c|}
\hline & \multicolumn{2}{|c|}{ Model 1} & \multicolumn{2}{|c|}{ Model 2} & \multicolumn{2}{|c|}{ Model 3} \\
\hline & OR & $95 \% \mathrm{Cl}$ & OR & $95 \% \mathrm{Cl}$ & OR & $95 \% \mathrm{Cl}$ \\
\hline CONTINUED skippers* & $2 \cdot 0$ & $1 \cdot 0,4 \cdot 2$ & $2 \cdot 3$ & $0 \cdot 9,6 \cdot 1$ & $1 \cdot 8$ & $0.5,6.2$ \\
\hline START all meals* & $1 \cdot 8$ & $0.7,4.9$ & 2.5 & $0 \cdot 7,8 \cdot 4$ & $1 \cdot 4$ & $0.3,7 \cdot 2$ \\
\hline STOP all meals* & 1.9 & $0 \cdot 8,4 \cdot 5$ & $3 \cdot 1$ & $1 \cdot 1,9 \cdot 0$ & $2 \cdot 8$ & $0.7,11.9$ \\
\hline ALL meals* & $1 \cdot 0$ & Ref. & $1 \cdot 0$ & Ref. & $1 \cdot 0$ & Ref. \\
\hline Physical activity & & & $0 \cdot 7$ & $0.6,0.9$ & $0 \cdot 6$ & $0 \cdot 4,0 \cdot 8$ \\
\hline Overweight in 4th grade & & & & & $58 \cdot 1$ & $21 \cdot 9,154 \cdot 1$ \\
\hline
\end{tabular}

Ref., reference category.

All three models were adjusted for gender and maternal education.

${ }^{\star}$ CONTINUED skippers = meal skippers at both time points; START all meals = meal skippers in 4th grade, eat all meals in 7th grade; STOP all meals = eat all meals in 4th grade, meal skippers in 7th grade; ALL meals = eat all meals at both time points. 
but contrary to the present study, a 9-year American longitudinal study described that this association was not significant after adjusting for physical activity ${ }^{(33)}$.

An important strength of the present study is the longitudinal design, which allowed for examining longterm associations between effects of meal regularity and overweight. The objective measurement of the children's weight and height at both time points, further categorized into BMI categories by international criteria ${ }^{(17,18)}$, is another major strength of the study.

A lack of statistically significant associations, despite a high odds ratio between irregular meal consumption and overweight in the analyses after adjusting for all confounders, may be explained by insufficient statistical power. The present study also has other limitations. First, it included the use of parental self-reported data. Although validated survey components were used, selfreported data may represent recall bias and response bias regarding dietary habits ${ }^{(34)}$. Under-reporting of food intake has been widely reported, and this is particularly evident for individuals who are overweight ${ }^{(6,7)}$. We cannot exclude the possibility that parents of overweight children may have under-reported unhealthy meal habits. However, this might be a minor problem in the present study as parents reported only meal habits and not detailed information about children's food intake. In Norway, there are no school-prepared meals, so most children bring their own lunchbox consisting of cold sandwiches. Most schools offer a milk prescription programme and water is available from the tap. Some misreporting of children's lunch consumption is likely, as parents normally are aware of what the children bring for lunch at school, but not if they actually eat it. In addition, the results from the present study may partly be limited by the sample size, i.e. a relatively low number of overweight children who were defined as meal skippers. Despite the limitations mentioned, few other longitudinal studies have focused on the association between meal pattern and overweight.

\section{Conclusion}

The present study showed significant increases in overall meal skipping among children between 4th and 7 th grade. The results indicate an association between overweight and meal skipping, but additional prospective and longitudinal analyses and intervention trials are warranted to confirm this relationship. The results indicate that a focus on a regular meal pattern should be considered when developing guidelines to prevent childhood overweight.

\section{Acknowledgements}

Sources of funding: This research was supported by Telemark University College, Telemark Hospital, the
Research Council of Norway and the Public Health Programme of Telemark. The Research Council of Norway and the Public Health Programme of Telemark had no role in the design, analysis or writing this article. Conflicts of interest: The authors certify that no actual or potential conflicts of interest in relation to this article exist. Ethics: The study was conducted according to the guidelines laid down in the Declaration of Helsinki. The research protocol was approved by the Regional Committee for Ethics in Medical Research and the Norwegian Data Inspectorate. Ethical approval and research clearance and were obtained from the Norwegian Social Science Data Services. Authors' contributions: I.M.O. and M.V.S. were responsible for the study design and data collection. T.H.S. and E.B. were responsible for the statistical analyses. All authors contributed to the interpretation of the results. T.H.S. and F.N.V. drafted the manuscript, and the other authors revised it critically. All authors read and approved the final version of the manuscript. Acknowledgements: The authors appreciate the cooperation of the children and their parents, the faculty and staff of the Telemark County primary and lower secondary schools, and the public health nurses who participated in the study.

\section{References}

1. Kremers SP, de Bruijn GJ, Visscher TL et al. (2006) Environmental influences on energy balance-related behaviors: a dual-process view. Int J Behav Nutr Phys Act 3, 9 .

2. Mota J, Fidalgo F, Silva R et al. (2008) Relationships between physical activity, obesity and meal frequency in adolescents. Ann Hum Biol 35, 1-10.

3. Nicklas TA, Morales M, Linares A et al. (2004) Children's meal patterns have changed over a 21-year period: the Bogalusa Heart Study. J Am Diet Assoc 104, 753-761.

4. Samdal O, Leversen I, Torsheim T et al. (2009) Trender $i$ helse og livsstil blant barn og unge 1985-2005. Norske resultater fra studien 'Helsevaner blant skoleelever. En WHO-undersøkelse i flere land' (The Health Behaviour in School-Aged Children: WHO Collaborative Cross-National Study (HBSC)). Bergen: Research Centre for Health Promotion, University of Bergen.

5. Øverby N \& Andersen LF (2002) Ungkost 2000 National Dietary Study Among Students in 4th and 8th Grade. Oslo: Directorate of Health and Social Affairs.

6. Lobstein T, Baur L \& Uauy R (2004) Obesity in children and young people: a crisis in public health. Obes Rev 5, Suppl. 1, 4-104.

7. Wang Y \& Lobstein T (2006) Worldwide trends in childhood overweight and obesity. Int J Pediatr Obes 1, 11-25.

8. Kosti RI \& Panagiotakos DB (2006) The epidemic of obesity in children and adolescents in the world. Cent Eur J Public Health 14, 151-159.

9. Han JC, Lawlor DA \& Kimm SY (2010) Childhood obesity. Lancet 375, 1737-1748.

10. Rokholm B, Baker JL \& Sørensen TI (2010) The levelling off of the obesity epidemic since the year 1999 - a review of evidence and perspectives. Obes Rev 11, 835-846.

11. Juliusson PB, Roelants M, Eide GE et al. (2007) Overweight and obesity in Norwegian children: secular trends in weightfor-height and skinfolds. Acta Paediatr 96, 1333-1337. 
12. Toschke AM, Kuchenhoff H, Koletzko B et al. (2005) Meal frequency and childhood obesity. Obes Res $\mathbf{1 3}$, 1932-1938.

13. Toschke AM, Thorsteinsdottir KH \& von Kries R (2009) Meal frequency, breakfast consumption and childhood obesity. Int J Pediatr Obes 4, 242-248.

14. Vik FN, Overby NC, Lien N et al. (2010) Number of meals eaten in relation to weight status among Norwegian adolescents. Scand J Public Health 38, Suppl. 5, 13-18.

15. Franko DL, Striegel-Moore RH, Thompson D et al. (2008) The relationship between meal frequency and body mass index in black and white adolescent girls: more is less. Int J Obes (Lond) 32, 23-29.

16. Singh AS, Mulder C, Twisk JW et al. (2008) Tracking of childhood overweight into adulthood: a systematic review of the literature. Obes Rev 9, 474-488.

17. Oellingrath IM, Svendsen MV \& Brantsater AL (2010) Eating patterns and overweight in 9- to 10-year-old children in Telemark County, Norway: a cross-sectional study. Eur J Clin Nutr 64, 1272-1279.

18. Oellingrath I, Svendsen M \& Brantsaeter AL (2011) Tracking of eating patterns and overweight - a follow-up study of Norwegian school children from middle childhood to early adolescence. Nutr J 10, 106.

19. Lillegaard IT, Overby NC \& Andersen LF (2012) Evaluation of a short food frequency questionnaire used among Norwegian children. Food Nutr Res 56, 1-9.

20. Schelling AB \& Streitlien A (2007) Utprøving av spørreskjema 'Kostholds- og måltidsmønster, fysisk aktivitet og vektutvikling' (Pilot study of the questionnaire 'Diet and eating patterns, physical activity and weight development'). Notodden: Telemark Educational Research.

21. Cole TJ, Flegal KM, Nicholls D et al. (2007) Body mass index cut offs to define thinness in children and adolescents: international survey. BMJ 335, 194.

22. Cole TJ, Bellizzi MC, Flegal KM et al. (2000) Establishing a standard definition for child overweight and obesity worldwide: international survey. BMJ 320, 1240-1243.

23. Dubois L, Girard M, Potvin Kent M et al. (2009) Breakfast skipping is associated with differences in meal patterns, macronutrient intakes and overweight among pre-school children. Public Health Nutr 12, 19-28.
24. Haapalahti M, Mykkänen H, Tikkanen S et al. (2003) Meal patterns and food use in 10- to 11-year-old Finnish children. Public Health Nutr 6, 365-370.

25. Sjoberg A, Hallberg L, Hoglund D et al. (2003) Meal pattern, food choice, nutrient intake and lifestyle factors in The Goteborg Adolescence Study. Eur J Clin Nutr 57, 1569-1578.

26. Samuelson G (2000) Dietary habits and nutritional status in adolescents over Europe. An overview of current studies in the Nordic countries. Eur J Clin Nutr 54, Suppl. 1, S21-S28.

27. Storey K, Forbes L, Fraser S et al. (2012) Adolescent weight status and related behavioural factors: web survey of physical activity and nutrition. $J$ Obes 2012, 342-386.

28. Rampersaud G, Pereira M, Girard B et al. (2005) Breakfast habits, nutritional status, body weight, and academic performance in children and adolescents. J Am Diet Assoc 105, 743-760.

29. Keski-Rahkonen A, Kaprio J, Rissanen A et al. (2003) Breakfast skipping and health-compromising behaviors in adolescents and adults. Eur J Clin Nutr 57, 842-853.

30. Croezen S, Visscher TLS, ter Bogt NCW et al. (2007) Skipping breakfast, alcohol consumption and physical inactivity as risk factors for overweight and obesity in adolescents: results of the E-MOVO project. Eur J Clin Nutr 63, 405-412.

31. Singh AS, Mulder C, Twisk JWR et al. (2007) Tracking of childhood overweight into adulthood: a systematic review of the literature. Obes Rev 9, 474-488.

32. Smith KJ, Gall SL, McNaughton SA et al. (2010) Skipping breakfast: longitudinal associations with cardiometabolic risk factors in the Childhood Determinants of Adult Health Study. Am J Clin Nutr 92, 1316-1325.

33. Affenito SG, Thompson DR, Barton BA et al. (2005) Breakfast consumption by African-American and white adolescent girls correlates positively with calcium and fiber intake and negatively with body mass index. $J$ Am Diet Assoc 105, 938-945.

34. Bandini LG, Must A, Cyr H et al. (2003) Longitudinal changes in the accuracy of reported energy intake in girls 10-15 y of age. Am J Clin Nutr 78, 480-484. 